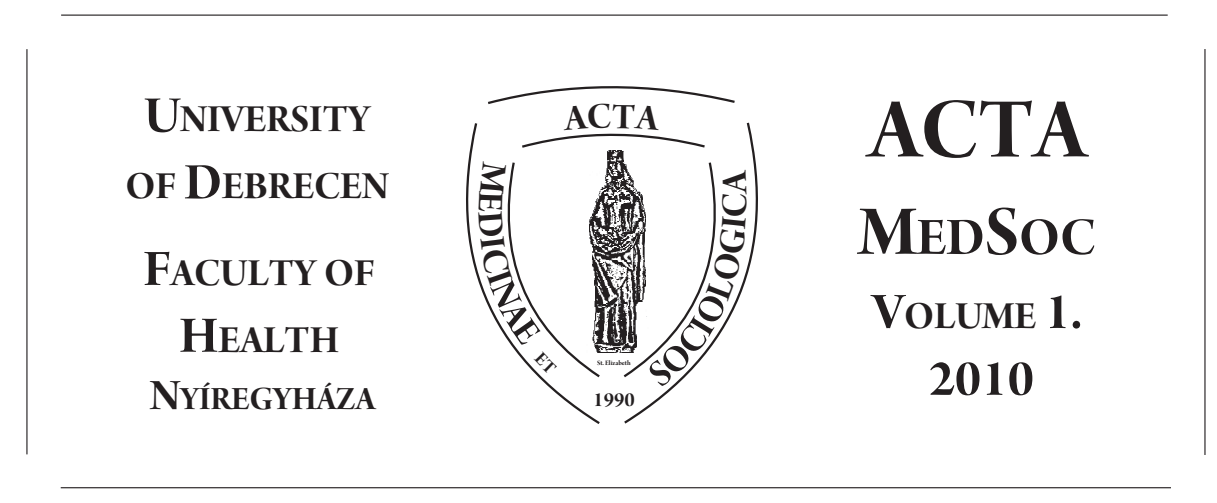

\title{
Operationalizing Codes of International Research Ethics: The Role of Social Work
}

\author{
Steve Drewry, Thomas R. Lawson \\ Social Work Program, Capital University; \\ Kent School of Social Work, University of Louisville \\ e-mail: sdrewry@capital.edu
}

\begin{abstract}
This article discusses ethical concepts common to international codes of research ethics and the potential difficulties that arise when ethical concepts are operationalized at the culture-specific level. Individual cultures are shaped largely by the social forces of history and circumstance, and the meaning systems of such cultures are embedded in the idiosyncrasies of a culture's language and symbols. Thus, broadly accepted principles of research ethics encounter problems of operationalization when divergent cultures attempt to attach unique cultural meaning to ethical principles such as voluntarism and informed consent. Social work, by virtue of its dedication to cultural relativism and regard for difference, is well positioned to facilitate the pragmatic implementation of ethical codes governing human subjects research as multinational research endeavors become more commonplace in an age of globalization.
\end{abstract}

Keywords: research, ethics, research ethics, social work, cultural relativism, inter-national research ethics

DOI: $10.19055 / \mathrm{ams} .2010 .1 / 1 / 3$ 
It has been the history of science and technology that the discovery of technological means to achieve scientific ends has outpaced the ethics which govern them (Murakami, 1995). In our time, human genome research is the most obvious example (Mandl, et al., 2003; Steinbrook, 2002; UNESCO, 1997; Weber, 2001), yet scientific history is replete with other instances where the exclamation, "We can do this!" has far preceded the question of "Ought we to do this?" (Grodin, 1995; Kimmel, 1988). Thus the history of science and ethics is one of which it can be fairly said that scientific experimentation has pushed the limits of the ethics which guide it at least as much as ethics and respect for human rights have structured and guided the research.

Promptly following World War II and the Nazi War Crime Tribunals, there arose the Nuremberg Code as a first step in codifying a set of principles to govern research activities involving human subjects (Amdur, 2003; Beals, Sebring \& Crawford, 1949; Gordon \& Prentice, 2000). Shortly thereafter, the General Assembly of the United Nations produced a universal declaration of human rights (1948). Both documents grew from a wellspring of outrage at the conduct of the Third Reich during World War II, and were written in the hope that institutionalized codifications of ethical behavior in scientific research and protection of human rights might abolish such atrocities forever. In 1964, the first Declaration of Helsinki (Tadd, 2000; World Medical Association, 2002) attempted to expand the rights of human research subjects and promote international compliance.

But here reside the origins of a problem. It is indeed well and good that international bodies such as the United Nations, the World Medical Association and numerous others have promulgated ethical codes to regulate scientific inquiry and protect human rights. Moreover, it is relatively simple to develop and ratify a set of ethical principles with which few reasonable people would disagree. The Nuremberg Code, the Declaration of Helsinki, and the American Belmont Report (1979), for instance, put forth these core tenets for the governance of scientific research involving human subjects:

1. Voluntary and informed consent for participation.

2. Anticipated benefits of human subjects research must outweigh anticipated risks.

3. Subjects of such research must have the option of withdrawing from research activities without penalty.

4. Risks and benefits of human subjects must be shared equally among people.

5. The rights of the individual supercede potential benefits to society.

6. Each research participant is entitled to the best available healthcare.

7. Research involving human subjects is to be guided by the principles of justice, beneficence and respect for persons. 
Who in good conscience could not agree with these principles? The precepts listed above are among the hallmarks of civil society, and time has demonstrated that nations which have refused assent to international codes of research ethics and shunned participation in dialogue regarding protection of human rights have been generally viewed as rogue states (Grodin \& Annas, 1996; House of Terror, 2002; Lozansky, 1989).

Conceptually, then, there appears to be more or less international agreement about the tenets underlying the ethics of human subjects research. We can come to consensus that the world community at least theoretically endorses an international code of research ethics.

\section{Putting Ethical Concepts into a Cultural Context}

How these codes of ethics are operationalized and implemented from country to country is a different matter entirely. In theory, concepts such as voluntarism, informed consent, favorable benefits-to-risk ratio, etc., are roughly translatable from language to language and culture to culture. But when these concepts are put into practice, the weight of culture and history shapes the meaning of concepts to the place and time of implementation.

For the profession of social work, this problem is interwoven with issues of preeminent importance to social work ethics, particularly as social work embraces a global and international sphere of practice (Hamalainen, 2002/2003). If social work research, and the professional ethics which govern and guide such an enterprise, is to lead the profession into the 21st century and an era of multinational collaboration in expanding the knowledge base of social work, then a workable code of international research ethics must be forged which respects both the traditions of the profession and the spirit of the profession's code of ethics (NASW Code of Ethics, 1999; Zahl, 2002/2003). Of particular import is the NASW Code's emphasis on protection of human subjects during research activities and social work's heightened regard for respect of cultural differences (Loewenberg, Dolgoff \& Harrington, 2000; NASW Code of Ethics, 1999).

For instance, the NASW Code speaks clearly and directly to the matters of client self-determination, respect for the dignity and worth of each person, regard for social and cultural diversity, and avoidance of conflicts of interest in professional practice. These tenets of ethical practice have correlates in the field of research ethics: voluntarism, informed consent, and the need for research integrity. One might argue that the NASW Code's section on research almost mirrors the Nuremberg Code. But a potential difficulty arises when we consider that voluntarism in one culture may have a vastly different meaning from that of another culture.

Additionally, if there is to surface a method by which international codes of research ethics governing the protection of human subjects are to be implemented at the cultural level, the voices of several distinct cultures must be heard in order to produce a genuinely meaningful set of guidelines to which multiple nations will 
adhere (Tadd, 2000). To do otherwise is tantamount to inflicting one culture's value system upon another's, and that is a slippery slope which all too frequently leads to the imposition of a moral hierarchy from one group of people upon another (Baker, 1998; Gergen, 1999). A brief review of the history of 20th century totalitarianism suggests the perils of such "othering" of different peoples and cultures when it is grounded in a stance of cultural, racial or moral superiority (Neuhaus, 1992; Riggins, 1997). Such practices are anathema to the spirit and the letter of the social work profession's mission, values and ethical standards (NASW Code of Ethics, 1999).

In a time of transnational cooperation among nations for purposes of economic development and social advancement, the international research community is experiencing an infusion of money that is often connected to a global sociopolitical agenda (European Commission, 2000, 2002; Kalantaridis, 2000). Also, many of the social and biomedical problems faced in the modern world have tentacles which stretch across cultures (e.g., SARS, AIDS), and require multinational collaboration to generate wide-ranging solutions (Coker \& McKee, 2001; Council for International Organizations of Medical Sciences, 2002; Dallia-Vorgia, et al., 2001).

In such a research environment, which nation's ethical protocols take precedence?

For instance, should funding for stem cell research emanate from an American source, but actually be conducted in Germany or Hungary, to which set of (necessarily culture-bound) research ethics would researchers need to comply? American, since the funding for the research grew from an American source with an American geopolitical agenda and a clearly defined and legislated human subjects system? Or German (or Hungarian), since the research is to be conducted within their respective national borders by native researchers with native research subjects, in a research environment with perhaps different human subjects protections, and almost certainly different research cultures?

History, politics, social culture and circumstance have shaped how different nations have elected to address the topic of operationalizing human subjects protection. Further, the scientific traditions of many nations vary considerably, and modern efforts in civil societies to protect the human subjects of research are imbedded in cultural contexts of near Talmudic complexity. These issues have immediate and direct implications for social work if the profession is to remain among the vanguard of meaningful social science research for the world community, yet stay true to the values underlying the NASW ethical code.

\section{Human Rights, Research Ethics and Social Work}

The history of social work is replete with examples of how the profession has committed itself to social change processes and the elevating of the human condition. Consider the historical origins of social work, born in the waning days of the 19th century amidst the progressive movement. Jane Addams and her settlement 
house movement were clearly engaged in social change, and helping immigrants become enfranchised American citizens was her fundamental purpose. Addams' desire to help those who had recently come to the United States was at its core an effort to secure the rights attendant to American citizenship for Chicago's newest denizens. While Addams has gained deserved notoriety for ensuring that immigrants had a place to find food and solace, it was her larger goal to help them assimilate into American life by learning how to speak, read and write English, and to ultimately find work to sustain themselves and their families in a new land.

As the profession matured, and the spirit of Addams' dream became manifest in such progressive social programs as those found in Franklin Roosevelt's New Deal, social work eventually became the gatekeeper for the network of social care infrastructure in the United States. Surely part of that function was to act as an agency of social control, in order to administer benefits to those most in need (Epstein, 1999). But just as importantly, social work became integral to the process by which human rights in America were safeguarded (Reichert, 2003).

\section{The NASW Code of Ethics}

We have only to look at the profession's code of ethics for evidence of this point. The ethical standard of the profession, the National Association of Social Workers' Code of Ethics (NASW, 1999), articulates very specifically the mission and values of social work. According to the NASW code, social work exists to promote social justice and social change on behalf of its clients, and to do so in such a way that clients are respected for their autonomy and diversity (NASW Code of Ethics, 1999). Moreover, the social work profession is dedicated to facilitating social change so that people become empowered to address their own needs. What drives social work is a set of core values, among which are service, social justice, regard for the dignity and worth of the individual, the importance of human relationships, integrity and competence in practice.

These core values are implemented through the fostering of certain key practices which operationalize the values of the profession: respect for individuals, commitment to client rights and self-determination, voluntarism, informed consent, regard for difference, avoidance of conflicts of interest, respect for privacy and confidentiality, records access, protection of vulnerable populations, practice competence, lack of discrimination, advocacy for social justice and research.

The value base and the key components of social work practice are obviously in line with such pivotal ethical documents as the Nuremberg Code, the Declaration of Helsinki, the Belmont Report, and virtually all of the modern human rights documents and legislation arising from the European Parliament and related deliberative bodies (European Parliament, 2001; Grigsby \& Roof, 1993).

Implicit in the social work code of ethics are the philosophical underpinnings we have found in other codes of ethics, particularly those which govern research involving human subjects (Freeman, 2000; Loewenberg, Dolgoff \& Harrington, 2000; 
Reamer, 1993). Kant's first principle, that an act is right if it is beneficent, is evident in social work's core values, put into practice according to the utilitarian/consequentialist tenet of greatest benefit to the greatest number, and applied evenly but with respect for cultural and individual differences such that no individual or culture is hierarchically superior to another (Freeman, 2000).

\section{Social Work Research}

The profession has matured since the days of Jane Addams and the progressive movement, to be sure. Yet Jane Addams' essential curiosity about the workable pragmatics of public service lives on in social work's commitment to research. Because social work is an eminently practical endeavor, the profession has long been concerned with the essence of applied research, the desire to determine what works. This sustained inquisitiveness has gained momentum in recent years, and while the issue of social work research has become highly politicized within the profession, it is undoubtedly the case that research will drive the profession for the foreseeable future (Gambrill, 1999; Myers \& Thyer, 1997).

Because research is such an integral part of social work, the NASW Code of Ethics specifies precisely how social work research is to be conducted. As we saw above, in our discussion of the relevance of the NASW code's tenets to the protection of human rights, the profession's code of ethics governing research activities echoes the principles espoused in the fundamental documents of human subjects protection: voluntarism, informed consent, no penalty for withdrawal or nonparticipation in research, favorable risk vs. benefit ratio, avoidance of undue inducement, protection of rights for research participants, protection from harm, and avoidance of dual relationships and conflicts of interest (NASW Code of Ethics, 1999).

Were we to overlay this ethical code for social work research upon the codes of ethics governing research involving human subjects that we have thus far considered, there would be a nearly exact match. It seems transparently clear that social work has done its homework insofar as the creation of a thoroughly up-to-date code of research ethics is concerned, and that social workers who adhere to the spirit and letter of the profession's code will be conducting research well within the boundaries of proper human subjects ethics.

\section{International Social Work and Cultural Relativism}

Yet the NASW Code of Ethics, laudable as it may be, is not the only pertinent document influencing the ethical behavior of social workers and social work researchers. The International Federation of Social Workers (IFSW) has promulgated a code of ethics for social workers that has worldwide implications (International Federation of Social Workers: Ethics in Social Work, 2004). The IFSW code of ethics is the child of the Universal Declaration of Human Rights (General As- 
sembly of the United Nations, 1948; Reichert, 2003). Predictably, it overtly places international social work ethics in a human rights context. Here are the IFSW core ethical principles: respect for the worth and dignity of the individual, client empowerment and self-determination, focus on client strengths, dedication to social justice, advocacy, and nondiscrimination, equitable distribution of resources and research risks/benefits, and commitment to human rights (International Federation of Social Workers: Ethics in Social Work, 2004).

Increasingly, the social work profession has expanded its focus to include service to other cultures. In the United States, social work has staked out its position regarding the importance of serving clients from a variety of ethnic and cultural backgrounds and presented its stance in the profession's code of ethics (NASW, 1999). As the demographic characteristics of America's population continue to change, the need for a flexible, culturally sensitive ethical code will only grow more relevant to practice with such a diverse group of people.

We live in an age of globalization. Today, the United States is no longer the cultural island of a century ago, divorced from the machinations of the old world, nor can it simply send its power "over there" to fight wars and then come home to an undisturbed idyll. America is part of the world like never before in its history, and one need only glance at today's newspaper headlines to see that the wages of isolationism and unilateral decision-making are too high to pay.

Whether it realizes it or not, the social work profession is part of this process. From its earliest beginnings, social work has had an international focus. The immigrants at Hull House came from all over Europe, and while Jane Addams' purpose may have been to help immigrants assimilate into everyday American life, she immediately faced the task of contending with a polyglot of cultures and diverse peoples. It is no different today. Modern social workers deal on a daily basis with clients from other nations and other continents, and it is incumbent on the social work profession to adjust its practices in light of cultural difference (Reichert, 2003; Wachholz \& Mullaly, 1997).

We have much to learn from other cultures, and the path to such learning is research. As we have seen, most ethical codes that structure and guide human subjects research share first principle commonalities, and at minimum imply a utilitarian world view concerning the betterment of humankind while simultaneously protecting individual human rights. There appears to be widespread consensus among ethicists regarding these two core philosophies of research ethics.

Within the realm of cultural relativism, though, lies a potential rub. One of the thematic currents running throughout modern times has been the influence of history and culture upon meaning construction within a given society. There can remain little doubt that meaning is indeed socially constructed through the interplay of a nation's history, traditions, culturally specific rituals, language and use of symbols. Thus experience itself is embedded within a culture's interwoven meaning context, and plays out in myriad forms of social interaction that are largely idiosyncratic to that culture but are nonetheless deeply entrenched in social 
norms, values and even the personal lives of a nation's citizenry. Unique culturally acquired meaning, then, is not to be taken lightly, for it is the glue which holds a society together.

The problem arises when one culture, for whatever reason, attempts to superimpose its meaning system upon another. How many times have we witnessed this phenomenon during the 20th and 21st centuries? Within cultures, the imposition of logical positivism upon the research communities of the social and behavioral sciences provides us with an example of an allegedly hierarchically superior world view shaping and molding a seemingly lesser subculture to its own image. There are in fact so many examples of this all too repetitive event that we may call it a commonplace of human interaction.

Many times, the power to oppress subcultures lies in one culture's superordinate meaning system and the raw power of its symbols. For instance, the German blitzkrieg of tanks and storm troopers was a very convincing display of the unquestionable supremacy of Hitler's war machine. Today, we see a similar manifestation in the currency of American financial power, and its capacity to influence world affairs with nearly the assurity of a tank assault.

It is not difficult to see, then, how one culture's interpretation of a widely accepted code of research ethics might supercede another's when such power disparities exist. Whose code of ethics, and culturally relative meaning system, takes precedence when nations work together to engage in scientific inquiry? What if the United States finances a research agenda in Hungary which, given its present state of fiscal need and its desire to bring in foreign investments to help rebuild the nation's infrastructure, could compromise the spirit of Act CLIV of 1997 on Health, which clearly specifies that nation's legal stance on human rights and human subjects protection in research? Indeed, Act CLIV impresses more stringent ethical requirements on Hungarian researchers than any American law governing research (Hungarian Parliament, 1997). Might Hungary's dedication to the preservation of human rights be contorted in the face of such alluring financial incentives? Or, more likely, would an American interpretation of how an ethical principle ought to be operationalized trump a Hungarian interpretation were there to be a substantial sum of money to tip the ethical scale?

Perhaps a partial resolution of this potential dilemma resides in a process of negotiated interpretation of the culturally specific meaning of an ethical concept, using as a moral rudder the most conservative operationalization of the research principle. Were there to exist a single most important guiding principle of ensuring that stringent codes of research ethics are applied sensitively but uniformly across cultures, it would be self-determination of the research participant. This is where social work makes a critically important contribution to the research protection process. 


\section{Social Work Ethics and Human Subjects Research}

The social work profession has a compelling history of dedication to human rights and amelioration of the human condition (Reichert, 2003). From its inception during the progressive era in the United States, through Alice Salomon's groundbreaking efforts to create schools of social work in Germany, to the modern era of Hungarian social workers dedicated to addressing the needs of the nonexistent in the aftermath of a perfect socialist state, social work has demonstrated an unwavering commitment to the betterment of the world's peoples (Hering \& Waaldijk, 2003).

But commitment in and of itself is inadequate to the task of protecting individual and collective rights in the context of human research studies. True enough, the principles of the Belmont Report (justice, beneficence and respect for persons) could have been written by social workers. The fit between the NASW Code of Ethics and the Belmont Report is that close. Also tight is the fit between the Nuremberg Code, the Declaration of Helsinki and the International Federation of Social Workers' ethical code (IFSW, 2004; NASW, 1999).

There are two additional concepts, deeply embedded in both the NASW and IFSW ethical codes, which position social work to operationalize codes of research ethics in a unique way. Social work's abiding belief in the right of client selfdetermination, which research ethics codifies as the principles of voluntarism and autonomy, makes this profession stand out in contrast to the implicit (and sometimes overt) paternalism of other helping professions. Medicine, and its affiliated professions, carries within its culture an unequal relationship between physician and patient. Presumably, this hierarchy is predicated upon the knowledge differential between healer and afflicted. Law, on the other hand, posits a similar relationship between attorney and client, with both being ultimately subservient to the law itself.

Social work has no such power or knowledge disparity. Yes, it is incumbent on social workers to possess sufficient training and expertise to facilitate change in their clients' lives. Yet the nature and process of such change is clearly client-driven, and the helping relationship between social worker and client is egalitarian. The client maintains the right of self-determination and autonomous decision-making. There is no implied contract between social worker and client that the social worker possesses greater knowledge about a client's situation or condition. Rather, the helping process is guided by client need, with the social worker's expertise as a commonly agreed upon map for change.

Likewise, the social work profession's belief in the importance of client diversity and respect for difference creates an environment that is significantly different from many other professions. In medicine, the positivistic underpinnings of the profession create a change environment that capitalizes, very effectively, upon the similarities among people. That is, ultimately, the power of logical positivism: it is founded upon the ways in which people are fundamentally the same. In the 
practice of law, and in the legal codification of human rights that typically exists in civil societies, each citizen is protected under law in precisely the same manner as every other. The power of such law is that it is indeed blind; that at least in theory, no one person is above or beneath the law.

Undoubtedly, these professions have contributed mightily to the betterment of humankind and the protection of individual and collective rights. Only social work, however, puts such steadfast emphasis upon the acknowledgement of human difference and its importance in understanding and helping people. And herein lies its great contribution to the operationalization of research ethics across cultures.

\section{Operationalizing Research Ethics: The Role of Social Work}

Social work can make a contribution to the operationalizing of international codes of research ethics in at least two ways. On the macro level of social work practice, the profession might participate in a research ethics tribunal, the model for which already exists in the European Union's research ethics council. The tribunal would be composed of research community representatives of nations engaged in transnational human subjects research, and have as its mission the adherence of each nation to a commonly accepted code of international research ethics.

Social work's part in this would be to mediate differences among the ethical codes of collaborating nations and facilitate mutually binding definitions of culturally relative concepts (e.g., informed consent). One of the profession's core competencies is that of negotiation, and while social work does not possess sole rights to negotiating skills, most social workers are fluent in the values, knowledge and skills necessary for successful resolution of differences. One of the functions social work could perform in this situation is stressing the validity of cultural relativism and the importance of difference in the international research context. This would create a climate for dialogue among representatives of different nations and potentially deflate the arguments that often ensue when one country's culture-bound beliefs come into conflict with another's.

On the micro practice level, social workers might lend these negotiating skills to competing or contending parties involved in the research endeavor itself. As we have seen, agreement on conceptual meanings of terms is not nearly so difficult as finding accord at the operational level. Social workers, as members of international research teams, may be well positioned to promote a workable consensus among team members immersed in research activities "on the ground." For instance, should American and Hungarian researchers be partnered in a research activity to examine student perceptions of power hierarchies in universities, social workers could be charged with ensuring that the more conservative definition of informed consent was adhered to in soliciting the participation of student research 
subjects, and that such consent was obtained in a culturally respectful manner that incorporated the idiosyncratic meaning systems of participants.

\section{Conclusion}

Social work is an applied profession. That is, social work is more concerned with how to apply knowledge than with who discovered or purports to own knowledge. It logically follows that an applied profession is well positioned to operationalize knowledge and apply it according to its ethical dictates.

The ethics of social work, particularly those mentioned above, guide the practice of every social worker. Client autonomy, self-determination, voluntary participation, the profession's devotion to social justice, and its essential respect for the dignity and worth of every individual's right to difference, are each core values of ethical social work practice. These values, as the IFSW's ethical code suggests, cross cultures and international boundaries. Regard for cultural relativism is ineradicably woven into the profession.

When we consider the part that social work might play in the operationalization of research ethics, regard for cultural relativism and respect for the integrity of difference are absolutely vital. Social workers possess the skills and the ethical commitment to facilitate the negotiation among cultures that is so necessary for respectful and workable application of ethical principles. Moreover, the profession's covenant with clients about the importance of egalitarian relationships helps mitigate the influence of power disparities. Lastly, social work's belief that client well being is the sine qua non of ethical practice has the capability to keep the research process focused precisely where it needs to be, on the primacy of human benefit for individuals who shoulder no unwarranted and unknown risk.

\section{References}

1. Amdur, R. (2003). Institutional review board: Member handbook. Sudbury, MA: Jones and Bartlett.

2. Baker, R. (1998). A theory of international bioethics: Multiculturalism, postmodernism, and the bankruptcy of fundamentalism. Kennedy Institute of Ethics Journal, 8(3), 201-231.

3. Beals, W., Sebring, H., \& Crawford, J. (1949). Permissible medical experiments (The Nuremberg Code). In Trials of war criminals before the Nuremberg military tribunals, 1946-1949, vol 2. Washington, DC: U.S. Government Printing Office.

4. Coker, R., \& McKee, M. (2001). Ethical approval for health research in central and eastern Europe: An international survey. Clinical Medicine, 1(3), 197-199.

5. Council for International Organizations of Medical Sciences. (2002). International ethical guidelines for biomedical research involving human subjects.

Retrieved June 7, 2003, from: 
http://www.cioms.ch/guidelines_nov_2002_blurb.htm

6. Dalla-Vorgia, P., Mason, S., Megone, C., Allmark, P., Bratlid, D., Gill, A., Morrogh, P., Plomer, A., \& Reiter-Theil, S. (2001). Overview of European legislation on informed consent for neonatal research. Archives of Disease in Childhood, 84(1), f70-f73.

7. Epstein, L. (1999). The culture of social work. In A. Chambron, A. Irving, \& L. Epstein (Eds.), Reading Foucault for social work (pp. 3-26). New York: Columbia University Press.

8. European Commission. (2000). European Group on Ethics: Statement of purpose and mission.

Retrieved June 12, 2003, from:

http://europa.eu.int/comm/european_group_ethics/gee1_en.htm

9. European Commission. (2002). Framework programme for research, 2002-2006:

An overview of opinions from national ethics committees.

Retrieved June 12, 2003, from:

http://biosociety.cordis.lu/docs.htm

10. European Parliament (2001). Charter of fundamental rights of the European Union. Retrieved June 8, 2003, from:

http://www.europarl.eu.int/charter.htm

11. Freeman, S. (2000). Ethics: An introduction to philosophy \& practice. Belmont, CA: Wadsworth.

12. Gambrill, E. (1999). Evidence-based practice: An alternative to authoritybased practice? Families in Society, 80(4), 341-350.

13. General Assembly of the United Nations. (1948). Universal Declaration of Human Rights. United Nations.

14. Gergen, K. (1999). An invitation to social construction.

Thousand Oaks, CA: Sage.

15. Gordon, B., \& Prentice, E. (2000). Protection of human subjects in the United States: A short history.

Journal of Public Health Management \& Practice, 6(6), 1-9.

16. Grigsby, R., \& Roof, H. (1993). Federal policy for the protection of human subjects: Applications to research on social work practice. Research on Social Work Practice, 3(4), 448-461.

17. Grodin, M. (1995). The historical and philosophical roots of bioethics. In M. Grodin (Ed.), Meta medical ethics: The philosophical foundations of bioethics. Dordrecht, The Netherlands: Kluwer Academic Publishers.

18. Grodin, M., \& Annas, G. (1996). Legacies of Nuremberg: Medical ethics and human rights. Journal of the American Medical Association, 276(20), 1682-1683.

19. Hamalainen, J. (2002/2003). Globalisation and classical models of social policy. IUC Journal of Social Work Theory and Practice.

Retrieved January 6, 2004, from:

http://www.bemidjistate.edu/sw_journal/issue6

20. Hering, S., \& Waaldijk, B. (Eds.) (2003). History of social work in Europe 
(1900-1960): Important female pioneers and their influence on the development of international social organizations. Opladen, Germany: Leske and Budrich.

21. House of Terror: Andrassy ut 60. (2002). [Brochure and various documents]. Budapest: Author.

22. Hungarian Parliament. (1997). Act CLIV of 1997 on Health: Biomedical research involving human subjects (Chs. 8-9). Retrieved June 12, 2003, from: http://www.eum.hu/eum/english/CLIV.htm

23. International Federation of Social Workers. (2004). Ethics in social work statement of principles. Retrieved January 27, 2004, from:

http://www.ifsw.org/GM-2004.html

24. Kalantaridis, C. (2000). Globalization and entrepreneurial response in postsocialist transformation: A case study from Transcarpathia, Ukraine. European Planning Studies, 8(3), 285-300.

25. Kimmel, A. (1988). Ethics and values in applied social research (3rd ed.). Newbury Park, CA: Sage, pp. 26-41.

26. Loewenberg, F., Dolgoff, R., \& Harrington, D. (2000). Ethical decisions for social work practice (6th ed.). Itasca, IL: F.E. Peacock.

27. Lozansky, T. (1989). The role of dissent in the Soviet Union since 1953. The Concord Review, 2(1), 1-22.

28. Mandl, J., Medve, L., Temesi, A., \& Vizi, E. (2003). Ethical regulation of biomedical research in Hungary. Orv. Hetil., 144(2), 73-76.

29. Murakami, Y. (1995). Science without conscience. Look Japan, 41(474), 3.

30. Myers, L., \& Thyer, B. (1997). Should social work clients have the right to effective treatment? Social Work, 42(3), 288-298.

31. National Association of Social Workers. (1999). NASW Code of Ethics. Washington, DC: NASW Press.

32. National Commission for the Protection of Human Subjects of Biomedical and Behavioral Research. (1979). The Belmont Report. National Institutes of Health. 33. Neuhaus, R. (1992). The way they were, the way we are. In A. Caplan (Ed.), When medicine went mad: Bioethics and the Holocaust (pp. 211-230). Totowa, NJ: Humana Press.

34. Reamer, F. (1993). The philosophical foundations of social work. New York: Columbia University Press, pp. 39-81.

35. Reichert, E. (2003). Social work and human rights: A foundation for policy and practice. New York: Columbia University Press.

36. Riggins, S. (1997). The language and politics of exclusion: Others in discourse. Thousand Oaks: Sage

37. Steinbrook, R. (2002). Improving protection for research subjects. New England Journal of Medicine, 346(18), 1425-1431.

38. Tadd, W. (2000). The Helsinki Declaration: Why all the fuss? Nursing Ethics, $7(5), 439-451$.

39. UNESCO. (1997). A universal declaration of the human genome and human rights: Rights of the person concerned. Retrieved June 13, 2003, from: 
http://www.ruhr-uni-bochum.de/zme/unesco.htm.

40. Wachholz, S., \& Mullaly, B. (1997). Human caring: Toward a research model for structural social work. Canadian Social Work Review, 14(1), 23-42.

41. Weber, W. (2001). Germany creates another bioethics advisory group. Lancet, $357(9267), 1512$.

42. World Medical Association. (2002). The declaration of Helsinki.

Retrieved June 7, 2003, from:

http://www.wma.net/e/policy/b3.htm

43. Zahl, M. (2002/2003). The impact of social policies on the formation of social work. IUC Journal of Social Work Theory and Practice.

Retrieved January 6, 2004, from:

http://www.bemidjistate.edu/sw_journal/issue5

Steve Drewry associate professor

Capital University, Columbus, Ohio, 43209, USA

Thomas R. Lawson professor

Kent School of Social Work - University of Louisville, Kentucky 